\title{
Should the Golden Spike glitter? Comments to the paper of M.-P. Aubry et al.
}

\author{
The problem is rather to place the Golden Spike in an intelligent manner.
}

\author{
by Jürgen Remane, Chairman of the International Commission on Stratigraphy (ICS)
}

\section{Foreword}

First of all I wish to thank M.-P. Aubry and her co-authors to have agreed in this new style of publication, discussing divergent views in a joint paper, where the reader may directly compare the arguments of both sides.

However, formulating a criticism of the paper of M.-P. Aubry, J. Van Couvering, W.A. Berggren, and F. Steininger proved to be unexpectedly difficult, because of its often polemic and rather emotional character. It contains also misleading citations, which give a wrong picture of the 1st edition of the International Statigraphic Guide (ISG, Hedberg, ed., 1976) as well as of the Guidelines of ICS (Cowie et al., 1986; Remane et al., 1996). This results in confusion and logical flaws, as will be shown in the following lines. I will proceed in three steps:

1) recall briefly what the Guidelines of ICS really mean;

2) comment upon specific points of the Aubry et al. paper, using the same chapter headings in order to facilitate the comparison of opposed views;

3) give a general appreciation in the Conclusions

\section{The Guidelines of ICS}

The Revised Guidelines of ICS (Remane et al., 1996) are easily accessible in Episodes. Controversial points were clarified by Remane (2000), see the Appendix. Only some basic premises, which are cited in the present paper of Aubry et al. in a misleading manner, will thus be reiterated here.

The Standard Global Chronostratigraphic Scale (SGCS) or Global Stratigraphic Scale (GSS) cannot be based on unit-stratotypes. There would inevitably be overlaps or gaps between successive units, which should be strictly contiguous. Boundary-stratotypes, i.e. GSSPs, are the only possible standard (see Hedberg, ed. 1976, Figure 13).

A blind choice of the boundary level would, however, be disadvantageous for the following chronostratigraphic correlations. Correlation must therefore precede definition. This statement has again led to confusion in the present paper of Aubry et al., although the Guidelines and Remane (2000) clearly state that the boundary is defined by a point in the rock and thus dissociated from the event, which had guided the choice of the boundary level. The GSSP is thus indeed "the only place where we actually know (by definition) that time and rock coincide". The criticism of the GSSP concept by Aubry et al. is invalid; the authors should have read the Guidelines and Remane (2000) carefully. The paper of Remane (2000) was presented on the Göteborg meeting in the presence of the first three authors of the "glittering golden spike" and the text was available in the Abstracts of the Göteborg meeting.

Everybody agrees that the stage is the basic unit of the SGCS. However, according to the Guidelines, this means simply that boundaries of all units of higher rank must correspond to stage boundaries. There is neither a technical nor a logical necessity to have the lowermost stage of such a unit defined in the first place. Otherwise the definition of the Paleocene/Eocene boundary would have to wait for another ten years.
Most of the traditional chronostratigraphic nomenclature dates from the century before the last. Many of these old stages, although imperfectly defined, are still in current use. A compromise has thus to be found between more or less conflicting current usages, which is not easy in the absence of formal priority rules in stratigraphy.

\section{Comments upon specific points}

\section{Abstract}

By referring to Hedberg (1976) without mentioning the 2nd edition of the ISG (Salvador, ed., 1996), the authors ignore 20 years of intensive work of the ISSC.

None of the statements concerning the 1st ISG and the Guidelines is substantiated by appropriate citations in the following text.

The Global Stratigraphic Scale (GSS) versus the Standard (or International) Global Chronostratigraphic Scale (SGCS)

Stratigraphy and time became intertwined for the first time with the discovery of the law of superposition by Steno in 1669.

Again: Why is the reader not informed about the existence of a 2nd edition of the ISG (Salvador, ed. 1996)? Is this because the GSSP concept has been incorporated there (Figure 2)?

\section{The Standard Global Chronostratigraphic Scale (SGCS)}

As to the stages "upon which chronostratigraphic units of higher rank are constructed", Hedberg (ed. 1976, p. 73) wrote also: "If stage subdivisions are lacking, the series may be defined independently by its own boundary-stratotypes."

There is a logical flaw in the last sentence: It is not the hierarchy which "ensures that no gap nor overlap occurs in the SGCS" but the fact that the units are based on boundary-stratotypes (i.e. GSSPs).

\section{The Global Stratigraphic Scale (GSS)}

\section{Last sentence:}

(1) Higher units defined independently from "existing" stage stratotypes: As long as there is no internationally agreed GSSP, there are no "existing stage stratotypes" (Remane, 2000). There is no rule of priority stipulating that a historic unit-stratotype should automatically determine the respective GSSP. Hedberg (ed., 1976, p. 19) states: "Priority in publication of a properly proposed, named and defined unit should be respected. However, the critical factors should always be the usefulness of the unit, the adequacy of its description, freedom from ambiguity, and suitability for widespread application. ... nor should an inadequately established name be preserved merely on account of priority."

(2) The question whether historic stages have to be adjusted to series boundaries, or if new stages or stage names have to be introduced, is a nomenclatural problem and a matter of pure convention which 
can be decided independently by a democratic vote. Note that the GSSP defining the base of the Neogene was placed at the level most favourable for worldwide correlation without ensuring that it corresponds exactly to the base of the historic Aquitanian. No stage names are mentioned in the figures (Steininger et al., 1997, 1st co-author M.-P. Aubry).

\section{Establishing chronostratigraphic units}

1st paragraph: The citation from the 1st ISG (p. 86) is selective and one-sided. See also (Hedberg ed., 1976, p. 71): "If major natural changes ("natural breaks") in the historical development of the Earth can be identified at specific points in sequences of continuous deposition, these may constitute desirable points for the boundary-stratotypes of stages." And, p. 84: "The boundary-stratotypes of chronostratigraphic units should be selected at or near markers favorable for long distance time-correlation."

If we believe Aubry et al. the ICS rules would request that "even well-documented and widely-used stages must be summarily modified". But if the lower boundary of the Ypresian sensu Aubry were well-documented and widely-used, it would have been supported by a majority of the Paleocene/Eocene Boundary Working Group.

4th paragraph: There seems to be disagreement among nannoplankton specialists about the reliability of Tribrachiatus digitalis. According to Monechi et al. (2000) the range of T. digitalis is poorly constrained due to preservational and taxonomic problems. According to von Salis et al. (2000) it is doubtful whether Rhomboaster and Tribrachiatus should be considered as distinct genera.

Figure 1 suggests (at least at first sight) that the FAD of $T$. digitalis lies below the base of the Mt. Héribu Member, high up in the Ieper Formation. The meaning of the Ieper clay mentioned in the figure caption remains unclear. Moreover, the question remains open how the LO of $T$. digitalis just above an important gap can be equated with the FAD of the species.

7th paragraph: There is no IUGS-ratified Ypresian stage. There is only a preliminary vote of the Paleogene Subcommission of ICS in 1989 that the Paleocene/Eocene boundary should correspond to the Thanetian/Ypresian boundary. Such decisions become formal only with the adoption of a GSSP through ICS and its ratification by IUGS.

8th paragraph: According to the authors, the base of the Eocene should coincide with the base of the historic Ypresian sensu Aubry. Whatever the exact meaning of the historic Ypresian may be, it has been defined in the North Sea Basin, which was paleogeographically fairly isolated at that stage of the opening of the Atlantic. The "new approach of ICS" would thus be just the opposite of what Aubry et al. pretend: In reality it is ICS which defends the global (i.e. a globally correlatable boundary level like the CIE) against the local Ypresian.

\section{The Global Standard Stratotype-section and Point (GSSP)}

2nd paragraph: The "boundary stratotype in the Guide", is said to represent a non pre-selected moment in time; but read the following passages of the 1st IGS (Hedberg ed., 1976):

p. 71 (chapter 7.c.3.b Boundaries and Stratotypes): "The boundary-stratotypes of a stage should be within sequences of continuous deposition - preferably marine - and both should be associated with distinct marker horizons such as biozone boundaries that can be readily recognized and widely traced as isochronous horizons" — and (still p. 71): "If major natural changes ("natural breaks") in the historical development of the Earth can be identified at specific points in sequences of continuous deposition, these may constitute desirable points for the boundary-stratotypes of stages." - and, p. 84: "The boundary-stratotypes of chronostratigraphic units should be selected at or near markers favorable for long distance time-correlation." Note the word "selected".

\section{Do GSSPs meet the needs of modern stratigraphy?}

\section{Historical priority}

2nd paragraph: What is the meaning of stratigraphy "being disconnected from its roots"? By the way, it has never been question of simply dismissing historic unit-stratotypes. But if they do not offer a starting point for a globally applicable definition, new solutions have to be found.

\section{Correlation precedes definition}

1st paragraph: The statement "that stratigraphy has changed from being a science of strata to being a science of boundaries": A discipline working with basic units which have no objectively and precisely defined boundaries, cannot pretend to be scientific. This fact has been neglected for a long time in chronostratigraphy and this has led to the chaos of chronostratigraphic nomenclature we currently live in. Before this omission has not been caught up with, stratigraphy cannot be the science of strata we would like it to be.

3rd paragraph: Constant confusion between definition and recognition of a boundary, incomprehension of the distinction between the events which have guided the choice of the boundary level and the subsequent boundary definition by a point in the rock.

Last paragraph: The meaning of the term "independent" is ambiguous. If "independent from any other form of stratigraphic unit" means that other forms of stratigraphic units may not simply be transformed into chronostratigraphic units, I agree. But definitions of chronostratigraphic units should not be (and have never been) independent of available methods of chronocorrelation. As to stability, the Guidelines state that a GSSP ratified by IUGS may not be changed arbitrarily.

\section{The best section}

Difficult to comment upon this rather vague and contradictory chapter. Unconformities as "horizons of reference". "Stratigraphy is not about the best section" - but why then are unit-stratotypes of stages "more fundamental to chronostratigraphy"?

\section{Discussion}

There are a lot of commonplace statements which can easily be agreed upon. The last sentence, however, seems to introduce a new perspective: "Chronostratigraphy is only meant to provide arbitrary levels for constant reference". GSSPs, too, provide levels for constant reference, inasmuch as a very formal international agreement is needed for changing them. So, does the word "arbitrary" mean that we should do away with the classical nested hierarchy of the SGCS (or GSS) and establish a new basis of chronostratigraphy? This approach would be worthwile being tested, although I doubt that it would allow to go beyond regionally limited schemes. And what would be the place of historic unit-stratotypes and of priority in this scheme?

\section{Conclusion}

A summary of the accusations already commented upon above. The more general aspects will be discussed in the following chapter.

\section{Conclusion and general appreciation}

At the end, the question remains: what is behind the violent attacks against ICS and the GSSP concept? I think the underlying problem is that a majority of the Paleocene/Eocene Boundary Working Group (PEBWG) is against the boundary level proposed by M.-P. Aubry, the Chairwoman of the PEBWG. The carbon isotope excursion, which can be correlated from marine to continental successions and which is supported by other nearby microfaunal and mammalian 
proxies, is the favourite of the group. This was already clear early in 1998, but two years of lengthy discussions did not bring convincing scientific arguments for the Ypresian base sensu Aubry. The problem was then placed on the "philosophical" level: Under the pretext of shortcomings of the GSSP concept the PEBWG was prevented from making a decision.

The problem of priority in chronostratigraphic nomenclature, addressed by Aubry et al. merits, however, some attention. Current usage should indeed be respected as far as possible. But it is a fact that there is no internationally agreed formal regulation of priority in stratigraphy. There is nothing like the International Codes of Zoological and Botanical Nomenclature. Moreover, these cannot serve as a model for chronostratigraphy. The biological codes are exclusively concerned with nomenclature and do not determine what should be the contents of taxonomic units. Scientists are free in deciding what is to be included in one species; and there are "splitters" and "lumpers". Chronostratigraphic/geochronologic units of the SGCS or GSS (whatever you want to call it) are units of measure. They cannot be quantified, like the meter and the second, but their scope must nevertheless be defined as precisely as possible. As shown above, this can only be achieved by internationally agreed boundary definitions, through GSSPs.

Priority means in practice that we have to make the best possible choice out of a wealth of historic stages, most of them defined more than a century ago under different theoretical premises. Most of these stages were delimited by stratigraphic gaps at their typelocalities, in perfect agreement with the catastrophist philosophy of that time. Stages were distinguished by their fossil contents from supposedly contiguous units. The importance of paleoecologic or paleobiogeographic factors responsible for faunal differences was often underestimated. Due to all this, there are overlaps or gaps between adjacent stages and different competing regional schemes for the same time interval. Arkell (1956, p. 8) mentions that 127 Jurassic stages have been proposed by different authors, concluding: "their very numbers proclaim futility."

A reduced number of stages (11 for the Jurassic) are now in general use for the current Phanerozoic systems/periods, but only 31 out of about 90 stage-boundaries are formally defined at the present date. And, as many of the current historic stages were defined in the classical region of central-northwest Europe, not all of them provide a sound basis for intercontinental correlation. Despite of these facts, certain names are deeply entrenched in the stratigraphic literature. This is the reason for the contradictory state of the GSS. But arbitrary priorities are certainly not a way out of this chaotic situation.

Nobody has so far proposed to forget all about the classical nomenclature and to start anew from zero, with new divisions bearing new names, preserving just the hierarchy as recommended by the ISG and the Guidelines. Only one entirely new name has so far been introduced in the GSS: the Gelasian as uppermost stage of the Pliocene (Rio et al., 1998). Otherwise there was an overwhelming preference for preserving classical names. But then the scope of stages had inevitably to be adapted to the revised boundaries.

The number of 20 GSSPs established since the first publication of the Guidelines (Cowie et al., 1986) demonstrates the utility of the GSSP concept. While adding the GSSA concept for the Precambrian, the Revised Guidelines (Remane et al., 1996) confirmed the GSSP concept of Cowie et al. (1986). They were thoroughly discussed within ICS and adopted in a formal vote with only one opposing ballot. Nevertheless, nothing is eternal, and constructive criticism of the Guidelines is certainly welcome. But in the present case, criticism has become polemic and is based on a strongly deformed picture of the Guidelines. This is regrettable, especially as the misinterpretations of the Guidelines had already been corrected by Remane (2000) and that, as stated above, the first three authors knew this publication. Their disregard is probably due to simple negligence, but the authors should be aware of the danger that this might be seen as a lack of scientific honesty, especially if the discussion is continued in this style.

\section{Appendix: Extract from Remane (2000)}

"Our traditional chronostratigraphic/ geochronologic scale of relative ages corresponds to a hierarchical system of named units. Stages/ages, the basic units for international use, can be characterized by their contents, but they are defined by their lower boundary which is in the same time the upper boundary of the underlying stage. This guarantees a time scale of strictly contiguous units, without gaps or overlaps. Each boundary is formally defined by a Global Standard Stratotype-section and Point, voted by ICS and ratified by IUGS. According to this concept, a boundary is defined by a point in the rock, the so-called "Golden Spike" in a stratotype section. The definition is not equated with any kind of events in Earth history, which might be interpreted in a different way by different scientists. All available methods may thus be used to correlate the boundary.

... A real problem is that the level designated by a GSSP will only be correlatable if it lies at or near events useful for interregional chronocorrelation (an evolutionary event, a magnetic reversal or some geochemical signal). Therefore, before making a definite choice among different candidates for a stage boundary, their correlation potentials have to be tested. In this sense, correlation precedes definition, but the definition (i.e. the GSSP) will then be dissociated from the markers which have guided the choice of the boundary level.

Problems (mainly problems of priority) also arise when classical stages are to be redefined more precisely, if we consider the shortcomings of historical unit stratotypes and the many conflicting traditional usages we are so often confronted with. Here one gets easily lost in a struggle with false problems ... These problems can be solved in a pragmatic approach, if we are aware of the fact that stages/ages are conventional units like the units of measure in physics. The establishment of the stratigraphic standard scale is not an end in itself, it has to provide research in Earth history with a workable standard of chronological reference."

\section{Additional references}

Arkell, W.J., 1956, Jurassic geology of the world, 806 pp., Oliver and Boyd Ltd., Edinburgh, London.

Monechi, S., Angori, E., and Speijer, R.P. , 2000, Upper Paleocene biostratigraphy in the Mediterranean region: Zonal markers, diachronism, and preservational problems., GFF, vol. 122, pp. 108-110.

Rio, D., Sprovieri, R., Castradori, D, and Di Stefano, E., 1998, The Gelasian (Upper Pliocene): A new unit of the global standard chronostratigraphic scale, Episodes, vol. 21/2, pp. 82-87.

Steininger, F.F., Aubry, M.P., Berggren, W.W., Biolzi, M., Borsetti, A.M., Cartlidge, J.E., Cati, F., Corfield, R., Gelati, R., Iaccarino, S., Napoleone, C., Ottner, F., Rögl, F., Roetzel, F., Spezzaferri, S., Tateo, F., Villa, G. and Zevenboom, D., 1997, The Global Stratotype Section and Point (GSSP) for the base of the Neogene, Episodes, vol. 20/1, pp. 23-28.

von Salis, K., Monechi, S., Bybell, L.M., Self-Trail, J., and Young, J., Remarks on the calcareous nannofossil markers Rhomboaster and Tribrachiatus around the Paleocene/Eocene boundary, GFF, vol. 122, pp. 138-140. 